\title{
Renoprotective and Blood Pressure Lowering Impact of Equisetum arvense and Viscum album Therapy in Experimental Model of Chronic Kidney Disease
}

\author{
Ülle Pechter ${ }^{*}$, Ingrid Kalev², Mai Ots-Rosenberg1 \\ ${ }^{1}$ Department of Internal Medicine, University of Tartu, Tartu, Estonia \\ ${ }^{2}$ Institute of General and Molecular Pathology, University of Tartu, Tartu, Estonia \\ Email: *ylle.pechter@kliinikum.ee
}

How to cite this paper: Pechter, Ü., Kalev, I. and Ots-Rosenberg, M. (2018) Renoprotective and Blood Pressure Lowering Impact of Equisetum arvense and Viscum album Therapy in Experimental Model of Chronic Kidney Disease. World Journal of Cardiovascular Diseases, 8, 545-556.

https://doi.org/10.4236/wjcd.2018.812054

Received: October 20, 2018

Accepted: December 21, 2018

Published: December 24, 2018

Copyright $\odot 2018$ by authors and Scientific Research Publishing Inc. This work is licensed under the Creative Commons Attribution International License (CC BY 4.0).

http://creativecommons.org/licenses/by/4.0/

(c) (i) Open Access

\begin{abstract}
Background: Chronic kidney disease (CKD) is an irreversible decline in the glomerular filtration due to nephrosclerosis and glomerular loss. Rat remnant kidney model enables to assess the benefits of different treatment possibilities. Aim: The aim of our study was to investigate renal morphology and functioning after 12 weeks of treatment with Equisetum arvense and Viscum album. Methods: Male Wistar rats with 5/6 nephrectomy received herbal drug preparation Equisetum/Viscum in a dosage of $0.007 \mathrm{~g} / \mathrm{kg} / \mathrm{die}$ (herbal group) or losartan (180 mg/l, ARB group) or remained untreated. Systolic blood pressure (SBP) and proteinuria were measured. Renal cortex tissue samples examined for focal-segmental glomerulosclerosis (FSGS) and interstitial fibrosis (IF). mRNA was isolated to estimate CCL2/MCP-1 gene transcription. Results: SBP was significantly lower both in herbal group and ARB group compared with untreated animals $(\mathrm{p}<0.05)$. The difference in proteinuria between herbal group and untreated group was significant $(p<0.05)$, between ARB group and untreated NPX ( $\mathrm{p}=0.001)$. Quantitative RT-PCR analysis revealed statistically significant differences of mRNA transcription for MCP-1 between herbal group and untreated group $(\mathrm{p}<0.05)$ and ARB group and untreated group ( $\mathrm{p}<0.001)$. FSGS (\%) and IF (scored 0 - 3) estimation in kidney tissue samples revealed that significantly less glomerulosclerosis was found and IF score was lower both in herbal group and ARB group compared to untreated group $(\mathrm{p}=0.001)$. Conclusions: We report about beneficial impact of horsetail Equisetum arvense and mistletoe Viscum album treatment on kidney functioning and morphology.
\end{abstract}




\section{Keywords}

Equisetum arvense, Experimental Chronic Kidney Disease, $M C P$-1 Relative Transcription, Viscum album

\section{Introduction}

Chronic kidney disease (CKD) is an irreversible decline in the glomerular filtration, due to glomerular loss and nephrosclerosis, irrespective of the underlying cause, progress relentlessly. The experimental model of progressive kidney disease (5/6 nephrectomy-NPX) is likewise characterized by severe renal lesions-glomerular hypertrophy, mesangial expansion, focal and segmental glomerular sclerosis, interstitial fibrosis, tubular atrophy and inflammation. NPX model enables the preclinical evaluation of the safety and possible benefits of different strategies, before introducing them in the care of chronic renal patients.

Herbal properties and therapeutic output of horsetail (Equisetum arvense) and mistletoe (Viscum album) are studied before they have shown diuretic, anti-hypertensive, anti-inflammatory [1] [2] [3], anti-diabetic, anti-toxic and immunomodulating properties. Extracts of Viscum album are widely studied for their complementary use in integrative therapy of cancer and other malignant disorders [4]-[18].

Herbal mixture preparation of horsetail Equisetum arvense and mistletoe Viscum album could be suggested as a complementary advice for chronic kidney disease (CKD) patients (http://www.wala.de/).

The aim of the study was to assess the effect of herbal drug combination Equisetum and Viscum treatment and to compare it with ARB treatment and non-treatment NPX group.

\section{Materials and Methods}

\subsection{Animals}

Male Wistar rats were purchased from the Laboratory Animal Center University of Kuopio, Finland. An acclimatization period of 10 days was allowed before any experiment work was undertaken. Rats were kept in a climate-controlled facility at the Faculty of Medicine of the University of Tartu where animals housed under standard conditions on a 12-h light/dark cycle and fed with standard rodent chow (R 70, Lactamin AB, Sweden) and had free access to tap water. The Animal Studies Ethics Committee in Estonia approved the study protocol.

\subsection{Experimental Design}

Rats $(\mathrm{n}=50)$, matched for age and body weight were randomly divided into four groups with 10 animals in each. Three groups $(n=30)$ were subjected to subtotal (5/6) nephrectomy (NPX) as described previously [19]. Randomly selected NPX groups received either ARB (ARB) or herbal treatment (Herbal); one NPX group remained untreated (untreated NPX). One group $(n=10)$ was sham operated 
control. One group $(\mathrm{n}=10)$ remained un-operated and untreated (Healthy). The animals were monitored for 12 weeks. Systolic blood pressure (SBP, $\mathrm{mmHg}$ ) was measured biweekly by the tail-cuff manometer (Harvard Apparatus, USA) in conscious pre-warmed rats. Measurement of SBP was repeated six to ten times and average value was noted for each animal. Proteinuria (U-prot, g/24 h) was measured at week 6 and 12 from urine collected for 24 hours using metabolic cages. Blood was collected from the aorta at the end of the study for serum creatinine (S-Crea, $\mu \mathrm{mol} / \mathrm{l})$. The kidney tissue samples were collected at the end of the study for histological examination and part of tissue were snap-frozen in liquid nitrogen for the assessment of $M C P-1$.

\subsection{ARB Treatment}

Treatment with ARB (losartan, $180 \mathrm{mg} / \mathrm{l}$ ) was added to the drinking water and started immediately after the operation. Drug solutions were freshly prepared daily prior to use.

\subsection{Herbal Treatment}

The animals received orally with drinking water the herbal drug preparation in a dosage of $0.007 \mathrm{~g} / \mathrm{kg} / \mathrm{die}$ using Equisetum/Viscum consisting equal doses of horsetail Equisetum arvense and mistletoe Viscum album substances that are prepared without alcohol and processed by heating, rhythmisising and potentising by WALA (Arzneimittelverzeichnis). Drug water-solutions were prepared daily prior to use. Treatment started immediately after the operation. Drug was not donated but bought from online pharmacy (eu-versandapotheke.com).

\subsection{Morphological Studies}

At the end of the study, rats were anesthetized and remnant kidneys removed, fixed in $10 \%$ buffered formaldehyde. Paraffin sections of coronal slices, through the pelvis of the remnant kidney, were cut at $4 \mathrm{~mm}$ thickness and stained using the periodic acid-Schiff (PAS) and Masson's trichrome methods.

Kidney sections were studied morphologically for evidence of focal-segmental glomerulosclerosis (FSGS), defined as glomeruli showing evidence of segmental or global collapse of capillaries with or without associated hyaline deposition and adhesions of the capillary tuft to Bowman's capsule. The extent of FSGS was expressed as a percentage of the total number of glomeruli counted ( $>50 /$ section). The presence of interstitial fibrosis (IF) was measured in trichrome stained sections from each kidney and was graded according to the following scale: 0 - no evidence of interstitial fibrosis; $1 .<25 \%$ involvement; 2 . $25 \%$ - 50\%; 3. $>50 \%$.

Quantification of rat $M C P-1 \mathrm{mRNA}$ by real time quantitative reverse transcriptase-polymerase chain reaction $(R T-P C R)$ :

For quantification of rat $M C P-1$, or alternatively $C c 2$ (monocyte chemoattractant protein-1 or $\mathrm{C}-\mathrm{C}$ chemokine ligand 2 in rat) and endogenous reference $\beta$-actin mRNAs, we used a SYBR Green real-time quantitative RT-PCR method with the ABI Prism 7000 Sequence Detection System (PE Applied Biosystems, 
Foster City, California). Total RNA was extracted from kidney tissue samples by using RNeasy Mini Kit (Qiagen, Hilden, Germany) and cDNA synthesized by a First-Strand cDNA Synthesis Kit SuperScriptTM III (Invitrogen). RNA was quantified by determination of ultraviolet absorbance at $260 \mathrm{~nm}$, and purity was assessed by measuring the optical density ratio at 260 and $280 \mathrm{~nm}$ (Nanodrop 2000, Thermo Fisher Scientific). Transcript levels for rat $M C P-1$ ( $C c h)$ and $\beta$-actin were quantified using SYBR Green-based quantitative real-time PCR technology. Amplification was performed by using the RT SYBR Green/ROX qPCR Master Mix (SABiosciences) and Real-Time RT ${ }^{2}$ qPCR Primer Assays. The polymerase chain reaction performed as described by producers [12] [20]. The $\mathrm{RT}^{2}$ qPCR oligonucleotide primer sets from SABiosciences are bioinformatically validated and give gene specific PCR amplicon products of the correct size and high amplification efficiency as a result. For amplification quality control we performed the dissociation curve program immediately after the above PCR program and carried out the agarose gel electrophoresis. Amplification efficiencies of endogenous reference and target sequence were comparable. mRNA level of the target sequence were normalized to those of $\beta$-actin as a housekeeping gene, and used as an endogenous internal control; the relative levels of each mRNA to that of $\beta$-actin were calculated. PCR reactions for both factors were repeated in triplicate.

\subsection{Statistical Analysis}

Data were analyzed at the end of the study period. Analysis of variance was used in statistical evaluation of the data using SPSS version 14.0. Data is presented as mean $\pm \mathrm{SD}$. The relative amount of $M C P-1(C c L)$ transcription in the rat kidney cortex probes was calculated using Delta-Delta $\mathrm{Ct}$ method. The difference in transcription level is given by $2^{-\Delta \Delta C t}$. Differences between groups were examined for statistical significance using Student t-test and Mann-Whitney U test. P < 0.05 was considered significant.

\section{Results}

Table 1 and Figure 1 present the body weight (BW) of rats measured currently during the study. Increase in weight was smaller in untreated NPX group and the animals significantly smaller at the end of the study $(\mathrm{p}<0.05)$ in untreated group compared with Herbal or ARB group. From NPX group 3 animals and from Herbal group 1 animal died before the end of the study, so these data was excluded from the results. Figure 1 illustrates increase of BW of study groups in timeline.

Average levels of systolic blood pressure (SBP) measured currently during the study showed that in the ARB group and herbal treatment group SBP was significantly lower compared with untreated animals $(\mathrm{p}<0.05)$ as demonstrated in Table 2 and Figure 2.

Serum creatinine elevation was noted in all NPX groups compared with healthy controls and sham operated groups, the elevation was most prominent in the NPX group, although not significantly different from other NPX groups 
Table 1. Body weights (BW, g). Treatment was started at week 0 after surgical NPX. There were no significant differences in BW among the groups at week 0 by ANOVA for repeated measures. At week 6 and week 12 the difference between untreated NPX group and other groups was significant $(\mathrm{p}<0.05)$. Sham operated and Healthy animals serve as illustrative controls.

\begin{tabular}{cccccc}
\hline & NPX-untreated & $\begin{array}{c}\text { NPX-Herbal } \\
\text { treated }\end{array}$ & $\begin{array}{c}\text { NPX-ARB } \\
\text { treated }\end{array}$ & Sham-operated & $\begin{array}{c}\text { Healthy } \\
\text { control }\end{array}$ \\
\hline Week 0 & $405.5 \pm 14.5$ & $349.2 \pm 4.8$ & $360.3 \pm 3.9$ & $371.4 \pm 4.5$ & $360.0 \pm 2.8$ \\
Week 2 & $425.5 \pm 4.6$ & $444.5 \pm 10.0$ & $388.0 \pm 5.0$ & $400.1 \pm 3.2$ & $400.0 \pm 10.1$ \\
Week 4 & $430.0 \pm 13.8$ & $420.0 \pm 12.8$ & $429.5 \pm 17.0$ & $458.0 \pm 11.7$ & $442.4 \pm 14.5$ \\
Week 6 & $441.1 \pm 10.8^{\star}$ & $490.9 \pm 9.8$ & $482.8 \pm 11.2$ & $500.0 \pm 12.2$ & $534.0 \pm 20.8$ \\
Week 12 & $466.0 \pm 6.7^{*}$ & $567.8 \pm 12.3$ & $540.5 \pm 19.6$ & $585.8 \pm 6.8$ & $576.8 \pm 20.8$ \\
\hline
\end{tabular}

Table 2. Systolic blood pressure (SBP, $\mathrm{mmHg}$ ), from week 2 on the difference between untreated NPX group and other groups was significant $(\mathrm{p}<0.05)$. Sham operated and Healthy animals serve as illustrative controls.

\begin{tabular}{cccccc}
\hline & NPX-untreated & $\begin{array}{c}\text { NPX-Herbal } \\
\text { treated }\end{array}$ & $\begin{array}{c}\text { NPX-ARB } \\
\text { treated }\end{array}$ & Sham-operated & $\begin{array}{c}\text { Healthy } \\
\text { control }\end{array}$ \\
\hline Week 0 & $128.3 \pm 6.2$ & $112.9 \pm 9.8$ & $100.0 \pm 1.0$ & $98.0 \pm 2.0$ & $90.3 \pm 12.2$ \\
Week 2 & $143.0 \pm 4.3^{*}$ & $100.0 \pm 10.2$ & $90.0 \pm 2.7$ & $100.2 \pm 9.8$ & $101.5 \pm 4.7$ \\
Week 4 & $150.3 \pm 3.8^{*}$ & $96.3 \pm 10.3$ & $110.1 \pm 6.0$ & $125.2 \pm 7.0$ & $113.1 \pm 2.7$ \\
Week 6 & $168.3 \pm 8.4^{*}$ & $101.6 \pm 8.4$ & $100.2 \pm 8.5$ & $112 \pm 8.3$ & $98.1 \pm 2.0$ \\
Week 12 & $177.7 \pm 4.9^{*}$ & $116.3 \pm 18.2$ & $102.3 \pm 13.1$ & $104.8 \pm 8.4$ & $100.8 \pm 8.2$ \\
\hline
\end{tabular}

Table 3. Proteinuria (U-Prot, g/24h) and serum creatinine (S-Crea, $\mu \mathrm{mol} / \mathrm{l}$ ) after 12 weeks of study period. The difference in proteinuria after 12 -week period between ARB-treated and untreated NPX rats was significant $\left({ }^{*} \mathrm{p}=0.001\right)$ and between Herbal treated and untreated NPX rats was significant $\left({ }^{\star *} \mathrm{p}<0.05\right)$ as well. In all NPX groups an increase in serum creatinine was noted in comparison with healthy controls, in the untreated NPX group the increase was most noticeable.

\begin{tabular}{cccccc}
\hline & NPX-untreated & $\begin{array}{c}\text { NPX-Herbal } \\
\text { treated }\end{array}$ & $\begin{array}{c}\text { NPX-ARB } \\
\text { treated }\end{array}$ & Sham-operated & $\begin{array}{c}\text { Healthy } \\
\text { control }\end{array}$ \\
\hline $\begin{array}{c}\text { U-Prot } \\
(\mathrm{g} / 24 \mathrm{~h})\end{array}$ & $10.09 \pm 3.13^{*}$ & $5.78 \pm 1.40^{\star *}$ & $2.08 \pm 1.01$ & $0.87 \pm 0.46$ & 00.00 \\
$\begin{array}{c}\text { S-Crea } \\
(\mu \mathrm{mol} / \mathrm{l})\end{array}$ & $99.40 \pm 28.89$ & $60.63 \pm 3.45$ & $57.40 \pm 5.66$ & $43.20 \pm 7.90$ & $31.4 \pm 7.23$ \\
\hline
\end{tabular}

(Table 3 and Figure 3). Urinary albumin excretion (U-Prot) was also increased in all NPX groups, but was significantly reduced in the ARB and Herbal treatment groups, compared with untreated animals $(\mathrm{p}<0.05)$, data shown in Table 3 and Figure 4.

FSGS and IF estimation in kidney tissue samples of NPX rats revealed that significantly less glomerulosclerosis was found and IF score was lower both in ARB-group and herbal group compared to untreated group as shown in Table 4, Figure 5 and Figure 6. 
Table 4. Focal-segmental glomerulosclerosis (FSGS), interstitial fibrosis (IF) and MCP-1 gene relative transcription in kidney tissue of NPX rats after 12 weeks of study period. The difference in FSGS between ARB-treated and untreated NPX rats was significant $\left({ }^{*} \mathrm{p}=0.001\right)$ and between Herbal treated and untreated NPX rats was significant $\left({ }^{\star} \mathrm{p}=0.001\right)$ as well. The difference in MCP-1 relative transcription after 12 -week period between Herbal treated and untreated NPX rats was significant $\left({ }^{\star} \mathrm{p}=\right.$ $0.001)$. Between ARB-treated and untreated NPX rats as well as sham-operated and healthy control was significant $\left({ }^{* *} \mathrm{p}<0.05\right)$ as well.

\begin{tabular}{cccccc}
\hline & NPX-untreated & $\begin{array}{c}\text { NPX-Herbal } \\
\text { treated }\end{array}$ & $\begin{array}{c}\text { NPX-ARB } \\
\text { treated }\end{array}$ & Sham-operated & $\begin{array}{c}\text { Healthy } \\
\text { control }\end{array}$ \\
\hline FSGS (\%) & $31.17 \pm 2.87$ & $7.11 \pm 1.29^{*}$ & $5.12 \pm 2.3^{*}$ & 0 & 0 \\
IF (0...3) & $1.33 \pm 0.48$ & $1.02 \pm 0.11$ & $0.1 \pm 0.1^{\star}$ & 0 & 0 \\
$\begin{array}{c}\text { MCP-1 relative } \\
\text { transcription }\end{array}$ & $3417 \pm 2240$ & $1680 \pm 862^{*}$ & $1038 \pm 588^{* *}$ & $974 \pm 236^{* *}$ & $1344 \pm 577^{* *}$ \\
\hline
\end{tabular}

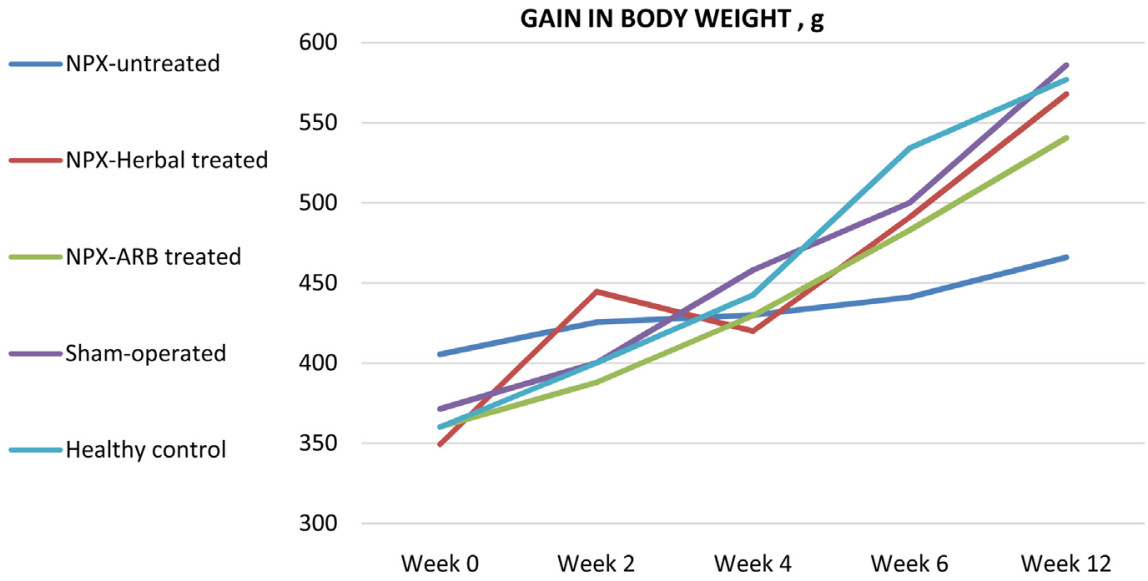

Figure 1. Gain in body weight during the study period of 12 weeks. The weight of NPX animals was significantly lower after 12 weeks.

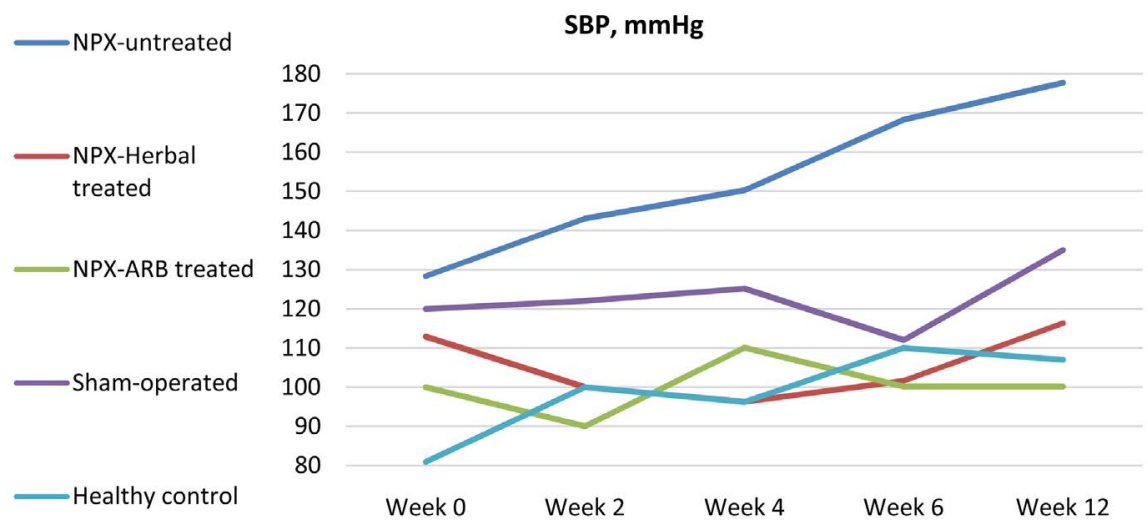

Figure 2. Changes in systolic blood pressure during the study period of 12 weeks. The SPB of untreated rats was significantly higher from week 4 in comparison with other groups.

Quantitative RT-PCR analysis revealed that the differences of mRNA transcription for $M C P-1$ between $\mathrm{ARB}$ treatment and untreated group were 
Serum creatinine (S-Crea, $\mu \mathrm{mol} / \mathrm{I})$

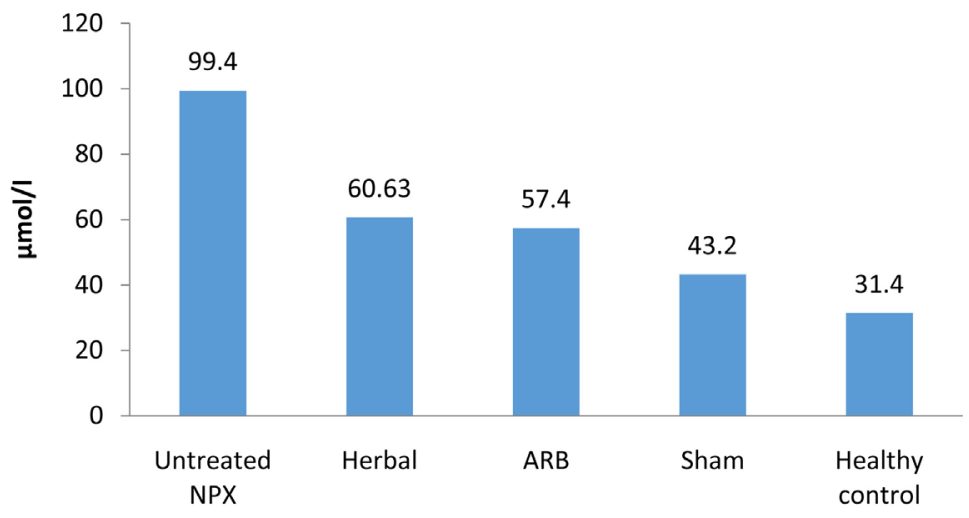

Figure 3. Serum creatinine at the end of the study. Serum creatinine elevation was noted in all NPX groups compared with healthy controls and sham operated groups, the elevation was most prominent in the NPX group, although not significantly different from other NPX groups.

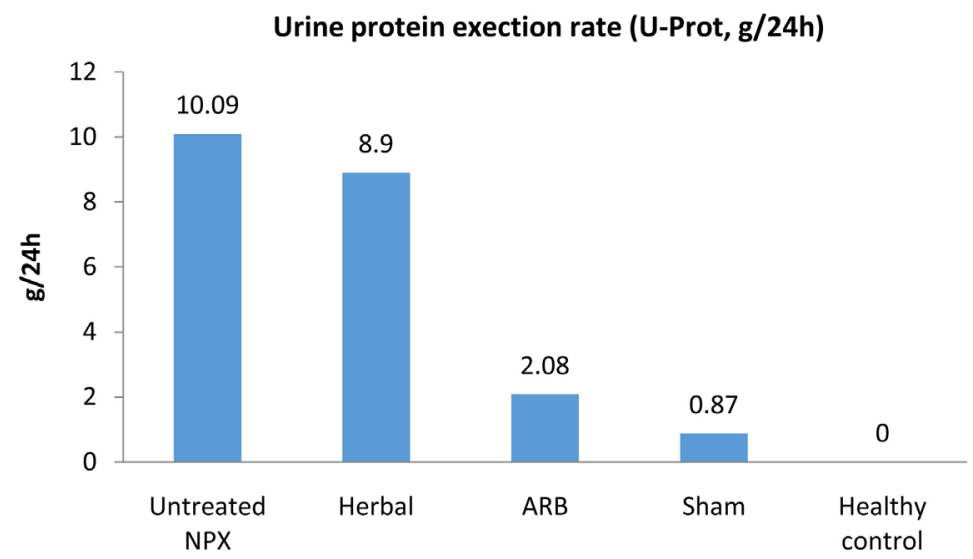

Figure 4. Urinary albumin excretion (U-Prot) was also increased in all NPX groups, but was significantly reduced in the ARB and Herbal treatment groups, compared with untreated animals $(\mathrm{p}<0.05)$.

Focal-segmental glomerulosclerosis (FSGS, \%)

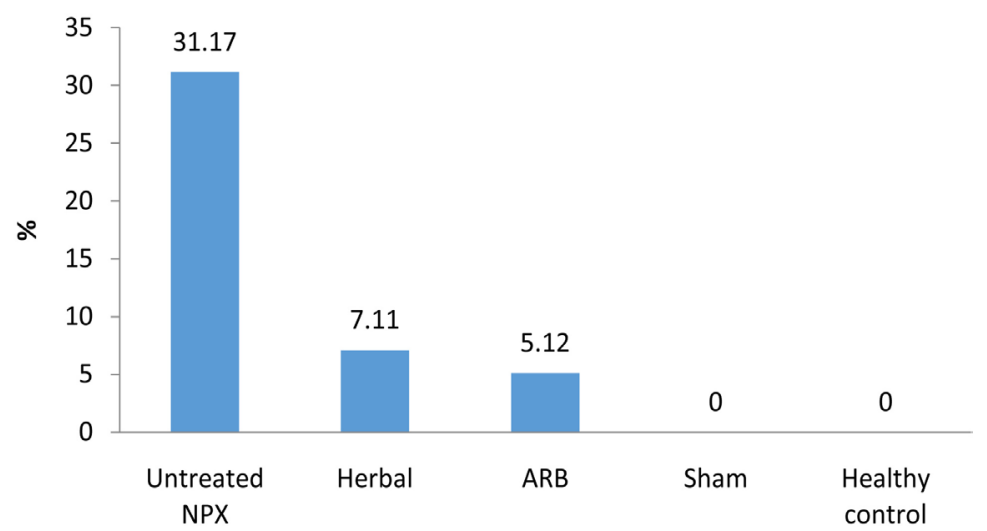

Figure 5. FSGS at the end of the study. Significantly less less glomerulosclerosis was found score was both in ARB-group and herbal group compared to untreated group. 
statistically highly significant $(\mathrm{p}<0.001)$, gene transcription was more than three times higher in untreated animals. Differences were revealed between herbal therapy and untreated group, being higher in untreated animals $(\mathrm{p}<0.05)$. Transcription differences according to the qPCR data between study groups are presented in Table 4 and Figure 7.

\section{Discussion}

We aimed in a 12-week experimental study in rats with 5/6 renal mass ablation (NPX) to compare the effect of ARB treatment and herbal mixture treatment of horsetail (Equisetum) and mistletoe (Viscum) in CKD experimental model with

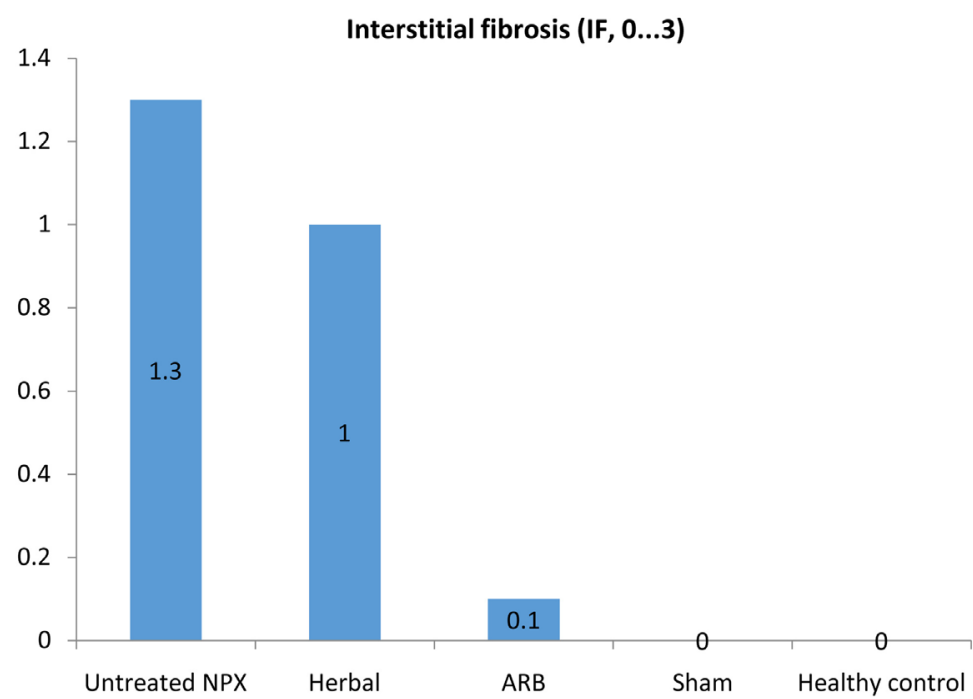

Figure 6. IF at the end of the study. Significantly less interstitial fibrosis was found in ARB group compared to untreated group.

$M C P-1$ gene relative transcription

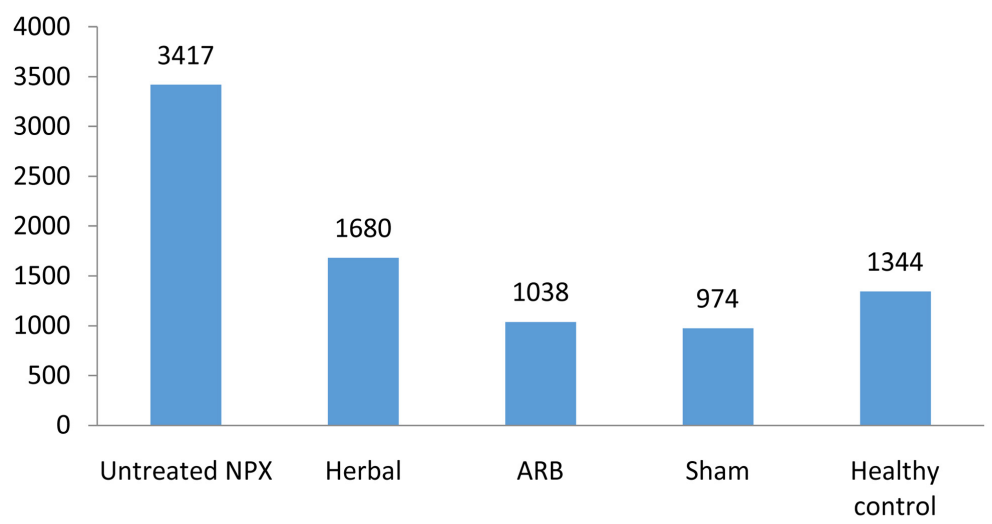

Figure 7. Quantitative RT-PCR analysis revealed that the differences of mRNA transcription for $M C P-1$ between ARB treatment and untreated group were statistically highly significant $(\mathrm{p}<0.001)$, gene transcription was more than three times higher in untreated animals. Differences were revealed between herbal therapy and untreated group, being higher in untreated animals $(\mathrm{p}<0.05)$. 
early development of hypertension and proteinuria and with progressive glomerulosclerosis, interstitial fibrosis, tubular atrophy and inflammation in remaining kidney tissue. Various large-scale studies assessing ARB treatment indicate that $\mathrm{ARB}$ slows the pace of progressive renal injury resulting from $\mathrm{CKD}$ of diverse aetiologies [19] [21]-[27].

Our study assessed and compared the impact of herbal treatment with horsetail (Equisetum) and mistletoe (Viscum) in NPX rats. Herbal properties and therapeutic output of both herbs are studied previously [4] [9], but there are no previous experimental studies about this particular combination of herbs, although, Masteikova $\mathrm{R}$ et al. suggest in an experimental study that the effect of herbal combination therapy with horsetail is better than the single herb alone [28].

We measured currently SPB and renal functional parameters, studied renal patomorphology and CCL2/MCP-1 gene transcription in renal tissue in NPX rats treated 12 weeks with herbal drug preparation in a dosage of 0.007 $\mathrm{g} / \mathrm{kg} / \mathrm{die}$ using Equisetum/Viscum consisting equal doses of horsetail Equisetum arvense and mistletoe Viscum album substances that are prepared without alcohol and processed by heating, rhythmisising and potentising by WALA (http://www.walaremedies.de/).

We compared the results with matched NPX controls remained untreated and with healthy animals.

We observed significantly lower blood pressure level in herbal therapy group in comparison with untreated group. We saw the tendency to lowering of proteinuria in herbal therapy group as well. Thus, we could speculate about ameliorating of glomerular hemodynamics due to herbal treatment.

Herbal treatment with horsetail and mistletoe, as described in methods, had modulated $M C P-1$ gene transcription.

We observed significant reduction of $M C P-1$ mRNA transcription compared with untreated animals, almost to the level of healthy control group. In addition to significant reduction of MCP-1, could be partly due to the impact on the pro-inflammatory gene transcription [29].

We are aware of several limitations concerning herbal treatment investigations. There are various techniques of how herbal drugs are prepared for administration. It is difficult to compare different studies. The quality of preparation of herbal drug is of outmost importance. The reason we used the combination medicine of WALA Remedies, Germany, is because of their ultimate care of quality and long practice in herbal drugs (http://www.walaremedies.de/).

Phytopharmaceuticals are common adjuvant therapies, but as complex mixtures with multiple targets they have not been systematically investigated. There is still need to have more evidence to provide scientific credence for the use of herbal medicines. It is important to investigate various beneficial mechanisms that could protect kidney tissue from progressive damage and could contribute to decelerate the progression of CKD. Our study with remnant kidney model of 
progressive kidney disease shows possible benefits of herbal treatment with mixed herbal solution of horsetail and mistletoe.

\section{Conclusion}

Based on the results of our study, we conclude that: SBP was significantly lowered; urinary albumin excretion was significantly reduced; estimated FSGS was significantly less prominent and $M C P$-1 gene transcription in renal tissue was lower in studied rat group treated with herbal combination of horsetail and mistletoe than in untreated NPX group.

\section{Acknowledgements}

The work was supported by the Estonian Scientific Foundation, grant No. 6806 and 6573. The authors thank Merck and Co., Inc. for supporting Losartan.

\section{Conflicts of Interest}

The authors declare no conflicts of interest regarding the publication of this paper.

\section{References}

[1] Spelman, K., Burns, J., Nichols, D., Winters, N., Ottersberg, S. and Tenborg, M. (2006) Modulation of Cytokine Expression by Traditional Medicines: A Review of Herbal Immunomodulators. Alternative Medicine Review, 11, 128-150.

[2] Oka, M., Tachibana, M., Noda, K., Inoue, N., Tanaka, M. and Kuwabara, K. (2007) Relevance of Anti-Reactive Oxygen Species Activity to Anti-Inflammatory Activity of Components of Eviprostat, a Phytotherapeutic Agent for Benign Prostatic Hyperplasia. Phytomedicine, 14, 465-472. https://doi.org/10.1016/j.phymed.2007.04.006

[3] Lyu, S.Y. and Park, W.B. (2009) Mistletoe Lectin Modulates Intestinal Epithelial Cell-Derived Cytokines and B Cell IgA Secretion. Archives of Pharmacal Research, 32, 443-451. https://doi.org/10.1007/s12272-009-1319-6

[4] Do Monte, F.H., dos Santos Jr., J.G., Russi, M., Lanziotti, V.M., Leal, L.K. and Cunha, G.M. (2004) Antinociceptive and Anti-Inflammatory Properties of the Hydroalcoholic Extract of Stems from Equisetum arvense L. in Mice. Pharmacological Research, 49, 239-243. https://doi.org/10.1016/j.phrs.2003.10.002

[5] Dos Santos Jr., J.G., Blanco, M.M., Do Monte, F.H., Russi, M., Lanziotti, V.M., Leal, L.K., et al. (2005) Sedative and Anticonvulsant Effects of Hydroalcoholic Extract of Equisetum arvense. Fitoterapia, 76, 508-513. https://doi.org/10.1016/j.fitote.2005.04.017

[6] Wright, C.I., Van-Buren, L., Kroner, C.I. and Koning, M.M. (2007) Herbal Medicines as Diuretics: A Review of the Scientific Evidence. Journal of Ethnopharmacology, 114, 1-31. https://doi.org/10.1016/j.jep.2007.07.023

[7] Safiyeh, S., Fathallah, F.B., Vahid, N., Hossine, N. and Habib, S.S. (2007) Antidiabetic Effect of Equisetum arvense L. (Equisetaceae) in Streptozotocin-Induced Diabetes in Male Rats. Pakistan Journal of Biological Sciences, 10, 1661-1666. https://doi.org/10.3923/pjbs.2007.1661.1666

[8] Tovchiga, O.V. and Shtrygol, S. (2009) Effect of Medicinal Plants on the Excretory 
renal Function (a Review). EksperimentaP naia i klinicheskaia farmakologiia, 72, 50-59.

[9] Radenkovic, M., Ivetic, V., Popovic, M., Brankovic, S. and Gvozdenovic, L. (2009) Effects of Mistletoe (Viscum album L., Loranthaceae) Extracts on Arterial Blood Pressure in Rats Treated with Atropine Sulfate and Hexocycline. Clinical and Experimental Hypertension, 31, 11-19. https://doi.org/10.1080/10641960802409820

[10] Stajner, D., Popovic, B.M., Canadanovic-Brunet, J. and Anackov, G. (2009) Exploring Equisetum arvense L., Equisetum ramosissimum L. and Equisetum telmateia L. as Sources of Natural Antioxidants. Phytotherapy Research, 23, 546-550. https://doi.org/10.1002/ptr.2682

[11] Melzer, J., Iten, F., Hostanska, K. and Saller, R. (2009) Efficacy and Safety of Mistletoe Preparations (Viscum album) for Patients with Cancer Diseases. A Systematic Review. Forschende Komplementärmedizin, 16, 217-226.

[12] Crescenti, A., Puiggros, F., Colome, A., Poch, J.A., Caimari, A., Bas, J., et al. (2015) Antiurolithiasic Effect of a Plant Mixture of Herniaria glabra, Agropyron repens, Equisetum arvense and Sambucus nigra (Herbensurina(R)) in the Prevention of Experimentally Induced Nephrolithiasis in Rats. Archivos Españoles de Urología, 68, 739-749.

[13] Kour, J., Ali, M.N., Ganaie, H.A. and Tabassum, N. (2017) Amelioration of the Cyclophosphamide Induced Genotoxic Damage in Mice by the Ethanolic Extract of Equisetum arvense. Toxicology Reports, 4, 226-233. https://doi.org/10.1016/j.toxrep.2017.05.001

[14] Hedaya, R. (2017) Five Herbs plus Thiamine Reduce Pain and Improve Functional Mobility in Patients with Pain: A Pilot Study. Alternative Therapies in Health and Medicine, 23, 14-19.

[15] Das, G., Patra, J.K. and Baek, K.H. (2017) Antibacterial Properties of Endophytic Bacteria Isolated from a Fern Species Equisetum arvense L. against Foodborne Pathogenic Bacteria Staphylococcus aureus and Escherichia coli O157:H7. Foodborne Pathogens and Disease, 14, 50-58. https://doi.org/10.1089/fpd.2016.2192

[16] Suveren, E., Baxter, G.F., Iskit, A.B. and Turker, A.U. (2017) Cardioprotective Effects of Viscum album L. Subsp. Album (European Misletoe) Leaf Extracts in Myocardial Ischemia and Reperfusion. Journal of Ethnopharmacology, 209, 203-209. https://doi.org/10.1016/j.jep.2017.07.010

[17] Xie, W., Adolf, J. and Melzig, M.F. (2017) Identification of Viscum album L. miRNAs and Prediction of Their Medicinal Values. PLOS ONE, 12, e0187776. https://doi.org/10.1371/journal.pone.0187776

[18] Saha, C., Das, M., Stephen-Victor, E., Friboulet, A., Bayry, J. and Kaveri, S.V. (2016) Differential Effects of Viscum album Preparations on the Maturation and Activation of Human Dendritic Cells and CD4(+) T Cell Responses. Molecules, 21. https://doi.org/10.3390/molecules21070912

[19] Ots, M., Mackenzie, H.S., Troy, J.L., Rennke, H.G. and Brenner, B.M. (1998) Effects of Combination Therapy with Enalapril and Losartan on the Rate of Progression of Renal Injury in Rats with 5/6 Renal MASS Ablation. Journals of the American Society of Nephrology, 9, 224-230.

[20] Mann, J.F., Green, D., Jamerson, K., Ruilope, L.M., Kuranoff, S.J., Littke, T., et al. (2010) Avosentan for Overt Diabetic Nephropathy. Journals of the American Society of Nephrology, 21, 527-535. https://doi.org/10.1681/ASN.2009060593

[21] Kato, S., Luyckx, V.A., Ots, M., Lee, K.W., Ziai, F., Troy, J.L., et al. (1999) Renin-Angiotensin Blockade Lowers MCP-1 Expression in Diabetic Rats. Kidney In- 
ternational, 56, 1037-1048. https://doi.org/10.1046/j.1523-1755.1999.00643.x

[22] Brenner, B.M., Cooper, M.E., de Zeeuw, D., Keane, W.F., Mitch, W.E., Parving, H.H., et al. (2001) Effects of Losartan on Renal and Cardiovascular Outcomes in Patients with Type 2 Diabetes and Nephropathy. The New England Journal of Medicine, 345, 861-869. https://doi.org/10.1056/NEJMoa011161

[23] Azushima, K., Gurley, S.B. and Coffman, T.M. (2018) Modelling Diabetic Nephropathy in Mice. Nature Reviews Nephrology, 14, 48-56. https://doi.org/10.1038/nrneph.2017.142

[24] Ahmed, A.K., Kamath, N.S., El Kossi, M. and El Nahas, A.M. (2010) The Impact of Stopping Inhibitors of the Renin-Angiotensin System in Patients with Advanced Chronic Kidney Disease. Nephrology Dialysis Transplantation, 25, 3977-3982. https://doi.org/10.1093/ndt/gfp511

[25] Majewski, C. and Bakris, G.L. (2016) Has RAAS Blockade Reached Its Limits in the Treatment of Diabetic Nephropathy? Current Diabetes Reports, 16, 24. https://doi.org/10.1007/s11892-016-0713-y

[26] Mann, J.F., Schmieder, R.E., McQueen, M., Dyal, L., Schumacher, H., Pogue, J., et al. (2008) Renal Outcomes with Telmisartan, Ramipril, or Both, in People at High Vascular Risk (the Ontarget Study): A Multicentre, Randomised, Double-Blind, Controlled Trial. The Lancet, 372, 547-553. https://doi.org/10.1016/S0140-6736(08)61236-2

[27] Xu, T., Sheng, Z. and Yao, L. (2017) Obesity-Related Glomerulopathy: Pathogenesis, Pathologic, Clinical Characteristics and Treatment. Frontiers in Medicine, 11, 340-348. https://doi.org/10.1007/s11684-017-0570-3

[28] Masteikova, R., Klimas, R., Samura, B.B., Savickas, A., Samura, B.A., Belaij, S.I., et al. (2007) An Orientational Examination of the Effects of Extracts from Mixtures of Herbal Drugs on Selected Renal Functions. Česká a Slovenská Farmacie, 56, 85-89.

[29] Bianconi, V., Sahebkar, A., Atkin, S.L. and Pirro, M. (2018) The Regulation and Importance of Monocyte Chemoattractant Protein-1. Current Opinion in Hematology, 25, 44-51. https://doi.org/10.1097/MOH.0000000000000389 